\title{
Detection of Low-Frequency Mutations in Exon 8 of the TP53 Gene by Constant Denaturant Capillary Electrophoresis (CDCE)
}

BioTechniques 27:128-135 (July 1999)

\author{
P.O. Ekstrøm A.-L. Børresen- \\ Dale $^{1}$, H. Qvist ${ }^{1}$, K.E. Gierck- \\ sky ${ }^{1}$ and W.G. Thilly \\ Massachusetts Institute of Tech- \\ nology, Cambridge, MA, USA \\ and ${ }^{~}$ The Norwegian Radium \\ Hospital, Oslo, Norway
}

\section{INTRODUCTION}

Detection of genetic changes has become an important field in biology and cancer research. A single-base mutation in DNA can lead to altered cellular behavior, which can induce oncogenesis if crucial genes are hit. Detection of such mutations might be beneficial for early diagnosis, prognosis and the evaluation of therapeutic outcome in cancer treatment. The possibility of low-frequency mutation detection is of particular interest both for early detection of malignant diseases, for evaluation of surgical margins and for monitoring relapse. The TP53 tumor-suppressor gene is commonly mutated in human cancer (11), and $30 \%-80 \%$ of human carcinomas contain sectors with a mutation in this gene, depending on the type and stage of the tumor investigated $(19,30)$. Mutation in TP53 has been found to be a prognostic factor in several cancers, but whether it is an independent prognostic factor, is not yet known $(1,4,22,25)$. Point mutations in the TP53 gene can confer characteristics of drug resistance or other phenotypes associated with prognosis in patient response to treatment $(1,3,31)$. It can be important to measure the distribution of such mutant cells in the periphery around excised tumors from the perspective of understanding tumor pathogenesis. It is also important to be able to discover small but potentially lethal sectors of tumors when the tumor area has been removed. Most of the mutations in the TP53 gene are reported to reside in the core region of the protein coding from exons 5 through 8 . This region is the most evolutionary conserved part of the gene (14).

Constant denaturant capillary electrophoresis (CDCE) has previously been used to analyze low-frequency mutations in the human mitochondrial genome with contiguous high- and lowmelting domains (17) and also used for mutation detection in the $\mathrm{N}$-ras oncogene with GC-rich primers (18). CDCE itself is an application of principles of cooperative equilibria to the separation of DNA sequences differing by as little as $1 \mathrm{bp}$ in 100. The first demonstration, by Fischer and Lerman (9), used a chemical denaturing gradient on a slab gel that was improved by elimination of the need for a gradient (15). The extension to capillary gel electrophoresis has increased the speed and resolution of the technology, and the use of laser-induced fluorescence has greatly increased general sensitivity (17).

The results from the present study revealed a fast and sensitive method for detection of point mutations in exon 8 of TP53 gene. This method is general for all DNA isomelting domains of 100-120 bp, and we are now extending the approach to other exons. When applied to the other conserved areas of the gene, we believe that this method can be used in molecular assessment in several clinical settings $(6,8,27)$.

\section{MATERIALS AND METHODS}

\section{Instrumentation}

The instrumentation was similar to the capillary electrophoresis instrument previously described by Khrapko et al. (17). Modifications were made for detection of tetramethylrhodamine (TMR) and fluorescein simultaneously. Lowpower argon laser (Omnichrome, Chino, CA, USA) with 515-nm wavelength was filtered through a 515-nm (10-nm 
bandwidth) filter (Corion, Franklin, MA, USA) and focused onto the capillary perpendicular to the microscope objective (Oriel Instruments, Stratford, CT, USA). The microscope objective focused emitted light onto a beam splitter (Type BS-550-S; Corion). Light from the beam splitter was then filtered through a 540-nm (10-nm bandwidth) filter (Corion), then through a filter removing wavelengths above $550 \mathrm{~nm}$ (Corion) and onto a Model 70680 Photo Multiplier (Oriel Instruments). The light emitted from the TMR fluorocrome was filtered through a 580-nm (10-nm bandwidth) filter (Corion) before reaching the second photo multiplier. Signals from the photo multipliers were amplified by a Model 70710 Current-Pre Amplifier (Oriel Instruments) and recorded as previously described $(17,18)$.

\section{Capillary Electrophoretic Conditions}

The coating of the fused silica capillary (Polymicro Technologies, Phoenix, AZ, USA) is based on the method described by Hjertén (13). Ten meters of capillary (inner diameter $75 \mu \mathrm{m}$ and outer diameter $363 \mu \mathrm{m}$ ) was used for the coating. The capillary was filled with $1 \mathrm{M} \mathrm{NaOH}$ and sealed off for $2 \mathrm{~h}$, and was then flushed with water before flushing with $1 \mathrm{M} \mathrm{HCl}$ for $2 \mathrm{~min}$. The capillary was then rinsed with water and $\mathrm{MeOH}$, injected with Silane (gmethacryloxypropyltrimethoxysilane) and sealed for $18 \mathrm{~h}$. The next day the



Figure 1. Detection of heteroduplexes (hd) when tumor cells (WiDr) are mixed with normal cells in ratio $\mathbf{1 0}^{-2}-\mathbf{1 0}^{-4}$. The $\mathrm{WiDr}$ cells have the mutation CGT $\rightarrow$ CAT in codon 273 (bp 14487). The ratio of $1 / 2$ the area under the mutant/WT heteroduplex peaks to the sum of all peaks can be used to estimate the mutant fraction for each mutation. In these examples, these ratios are $0.06 / 5.9$ equals approximately $10^{-2}$, and $0.02 / 17.2$ equals approximately $10^{-3}$. capillary was rinsed with $\mathrm{MeOH}$ and water. A $6 \%$ acrylamide solution (without $N, N^{\prime}$ methylenbisacrylamide) in $1 \times$ TBE buffer ( $89 \mathrm{mM}$ Tris-base, $89 \mathrm{mM}$ boric acid, $2 \mathrm{mM}$ ethylenediamine tetraacetic acid, $\mathrm{pH}$ ca. 8.3) containing $1 \mu \mathrm{L} N, N, N^{\prime}, N^{\prime}$-tetramethylethylenediamine (TEMED) and $1 \mathrm{mg}$ potassium persulfate per $\mathrm{mL}$ solution was injected. After polymerization, the capillary was cut in the desired length $(0.3 \mathrm{~m})$, and a window for detection was made with a scalpel. Replaceable linear polyacrylamide (LPA) was made according to Ruiz et al. (26), however, without urea and formamide. LPA was replaced before every run.

Electroinjection of the sample was accomplished by applying $2 \mu \mathrm{A}$ for 30 or $60 \mathrm{~s}$. The electrophoretic condition was a constant current of $8 \mu \mathrm{A}$, and the total length of the capillary was 0.3 with $0.1 \mathrm{~m}$ effective heated length. The heated zone was made with a metal jacket temperature controlled with circulating water from a water bath. Temperature in the water bath was set to $76^{\circ} \mathrm{C}$, but due to heat loss in the tubing, the effective melting temperature in the column was $75.5^{\circ} \mathrm{C}$.

\section{Cell Line and Patient Samples}

A colon cancer cell line, WiDr (Catalog No. CCL-218; ATCC, Rockville, MD, USA) was cultivated at $37^{\circ} \mathrm{C}$ in Eagle's minimum essential media (EMEM) medium with $10 \%$ fetal calf serum. Cells were frozen and thawed using the described protocol (2). Normal bone marrow cells were obtained from a noncancerous patient and were isolated using Lymphoprep ${ }^{\mathrm{TM}}$ (NYCOMED AS Pharma, Oslo, Norway). The WiDr and the normal cells were used in reconstruction experiments. WiDr cells were counted by microscope in a counting chamber and added in ratio of $10^{-2}, 10^{-3}, 10^{-4}$ and $10^{-5}$ into a total of $10^{7}$ normal cells.

A second reconstruction experiment was performed by mixing homoduplex mutated and wild-type (WT) polymerase chain reaction (PCR) products in ratio (mutated/WT) 1/10, 1/100, 1/1000 and $1 / 10000$, followed by formation of heteroduplexes by boiling and re-annealing. The number of PCR copies was estimated from the area under the curve 
of the electropherogram. To obtain different mutations, DNA from colon carcinomas from a patient cohort previously described (29) were also used in this study. Isolation of DNA was accomplished by standard phenol/chloroformextraction and ethanol-precipitation using an ABI 340A DNA Extractor (PE Biosystems, Foster City, CA, USA).

\section{PCR}

PCR of exon 8 of the TP53 gene was performed using the high-fidelity enzyme, Pfu DNA Polymerase (Stratagene, La Jolla, CA, USA) and the corresponding $P f u$ buffer from Stratagene. We used 20-mer fluorescent-labeled primer (MedProbe, Oslo, Norway) for the amplification $\left(5^{\prime}\right.$-F-ATCCTGAGTAGTGGTAATCT-3', F = fluorescent, fluorescein or TMR) together with a primer with high-melting domain (GC-rich sequence, 5'-CGCCCGCCGCGCCCCGCGCCCGTCCCGCCGCCCCCGCCCGTACCTCGCTT-
AGTGCTCCCT-3') previously described (5). Amplification was performed in a GeneAmp ${ }^{\circledR} 9600$ Thermal Cycler (PE Biosystems), using the following program: $120 \mathrm{~s}$ at $94^{\circ} \mathrm{C}, 35 \mathrm{cy}$ cles of $75 \mathrm{~s}$ at $94^{\circ} \mathrm{C}, 75 \mathrm{~s}$ at $55^{\circ} \mathrm{C}$ and $60 \mathrm{~s}$ at $72^{\circ} \mathrm{C}$. Heteroduplex formation between WT and mutation was produced by heating the PCR product to $94^{\circ} \mathrm{C}$ for $3 \mathrm{~min}$ and allowing re-anneal-

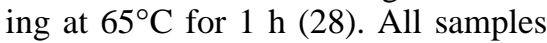
were processed in duplicates and analyzed twice.

\section{RESULTS}

The equilibrium melting temperature of a DNA sequence can be calculated using statistical mechanical principles coupled with knowledge of the free energy for melting any particular base pair (24). The theoretical melting temperature was calculated as $77.5^{\circ} \mathrm{C}$ for TP53 exon 8 when attached to a high-melting primer (5). Under separat-



Figure 2 Differences in the peak patterns for different point mutations in codon 273 (bp 14486 and 14487 ) in exon 8 of the TP53 gene. The DNA was amplified from tumor samples with different known mutations. ing condition (i.e., the right temperature in capillary), low-melting domain of the PCR product will unwind, while the high-melting domain will keep the strands together. This will allow for separation of more and less stable mutants and heteroduplexes compared to the WT. The temperature used in CDCE analysis was obtained by increasing the temperature in $0.5^{\circ} \mathrm{C}$ increments from $72^{\circ} \mathrm{C}$ until $80^{\circ} \mathrm{C}$ (data not shown). Variations in temperature between $75^{\circ}$ and $77^{\circ} \mathrm{C}$ affected the separation of the peaks. The final optimal temperature was $76^{\circ} \mathrm{C}$ and was used in the further CDCE analysis.

Figure 1 displays the detection of mutant PCR fragments when WiDr tumor cells are mixed with normal cells in various ratios. When $10^{4}$ mutated $\mathrm{WiDr}$ cells are mixed with $10^{7}$ normal cells, giving a ratio $10^{-3}$ before extraction of DNA, the mutation could be detected repeatedly. Titration down to $10^{-4} \mathrm{dem}-$ onstrated a loss of signal.

Alteration of a single base in the low-melting domain of the fragment to be analyzed will alter the melting behavior of most mutant homoduplexes and all mutant/WT heteroduplexes, respectively. Each mutation will consequently reveal a specific peak (homoduplex) or peaks (heteroduplexes) in the electropherogram, depending on whether or not the mutants have been transformed into heteroduplexes with excess WT DNA. Figure 2 shows some examples of different patterns as a consequence of base pair changes in codon 273 (bp 14 486 and 14487). DNA from ten other tumor samples harboring different mutations from codon 266 to codon 286 were also analyzed (data not shown). All the mutations we have analyzed so far have displayed a distinct peak pattern with regard to homo- and heteroduplexes.

Provisional identification of mutant homoduplexes can be performed by comparison of the elution time of a sample peak to that of a co-injected, but differentially labeled, authentic standard mutant DNA sequence. In our apparatus, we labeled samples with fluorescein and standards with TMR. By recording at two separate appropriate wave bands, we can differentiate between sample and standard signals. Figure 3 shows an example. In Figure 3, the middle electropherogram displays a 
WT peak in the TMR channel. This peak co-migrates with the first peak in the samples, indicating that it is the WT homoduplex. Note the cross-talk from the fluorescein in the TMR channel. This is due to the detection of some of the emitted light from the excitated fluorescein molecule in the TMR detector. To distinguish between cross-talk and true peaks in the TMR channel, the ratio of the two channel signals are plotted in the lower panel. When the ratio displays a negative peak, this signifies a true signal in the TMR channel. A mutationspecific pattern can also be used to identify unknown mutations under the assumption that there is a specific pattern for each mutation and a database for all mutations is available. In Figure 4 , the peak pattern from a sample with an unknown mutation is displayed in the upper panel. In the middle and lower panels, the PCR product from the sample is mixed with PCR products from two known mutant samples. The mutant in the middle electropherogram has a $\mathrm{C} \underline{\mathrm{CT}} \rightarrow \mathrm{CA}$ T base change in codon 278 (bp 14502). The electropherogram displays one WT peak, two peaks representing mutation and four heteroduplexes. In the lower electropherogram, the test sample was mixed with a mutant


codon 282 (bp 14513). This electropherogram revealed only four peaks, indicating that the same mutation was present in both of the mixed samples. By sequencing the unknown sample, the mutation was identified as $\underline{\mathrm{CGG}} \rightarrow \underline{\mathrm{T} G G}$ base change in codon 282 .

\section{DISCUSSION}

In this study, we have applied high-fidelity PCR with fluorescent primer, CDCE and laser-induced fluorescence for detection of mutations in exon 8 in the TP53 gene. Separation of mutants from WT were performed in a

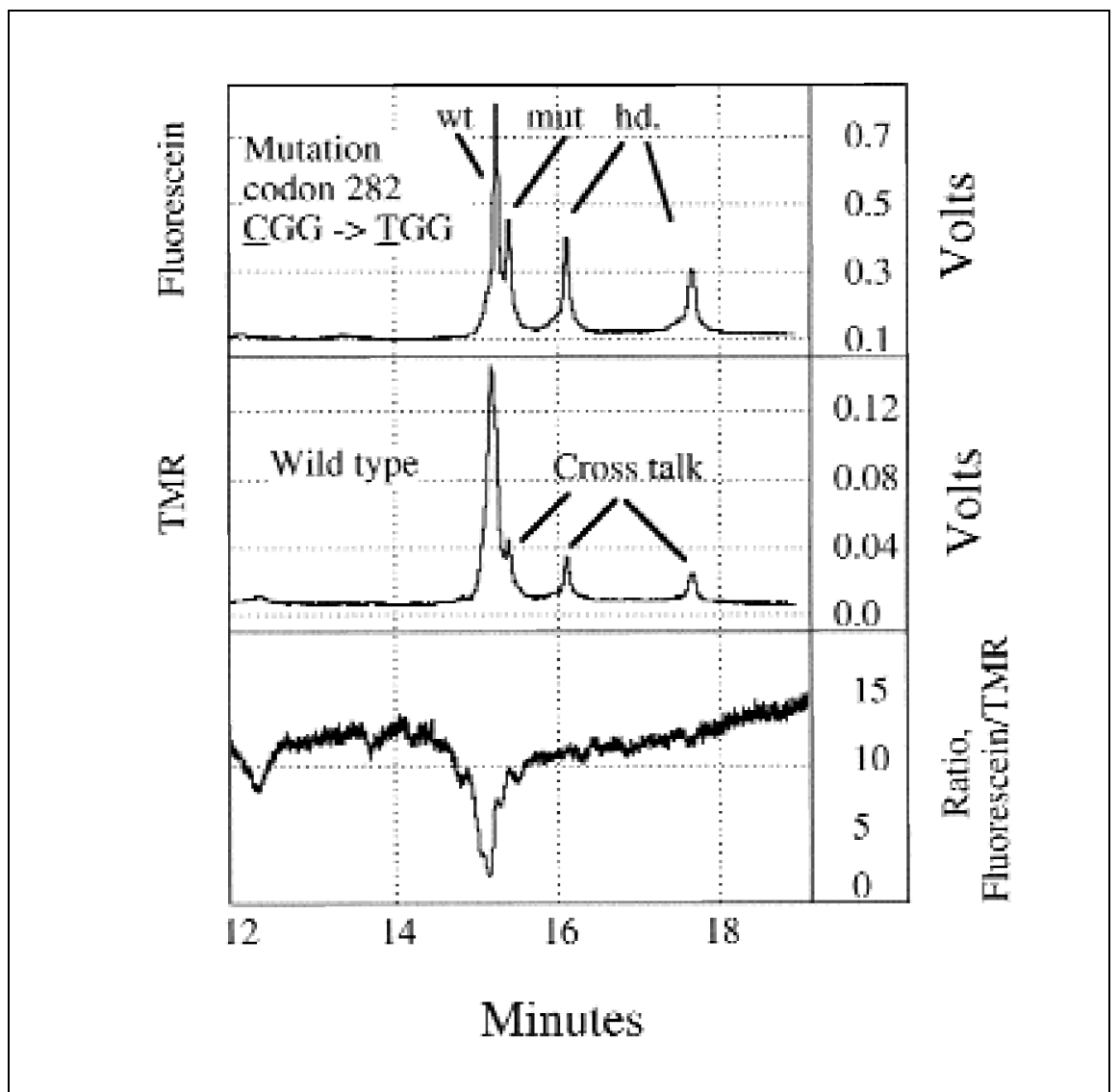

Figure 3. Provisional peak identification by running WT standard in the TMR channel (middle panel). Mutation is $\underline{\mathrm{CGG}} \rightarrow \underline{\mathrm{TGG}}$ in codon 282 (bp 14513) (upper panel). Note the cross-talk from the fluorescein channel onto the TMR channel. 
temperature-controlled denaturing zone. The melting of the DNA (PCR product) was based on heat only, as no chemical denaturant was added. This gave better control over the denaturant conditions in the capillary. The temperature $\left(75.5^{\circ} \mathrm{C}\right)$ used for denaturation was slightly lower than the theoretical melting temperature $\left(77.5^{\circ} \mathrm{C}\right)$, calculated by a melting program (5). The sensitivity of the CDCE/laser-induced fluorescence (LIF) system for detection of low-frequency mutation in presence of WT was evaluated by mixing tumor cells with normal cells in a ratio from $10^{-2}$ and as low as $10^{-4}$ (tumor cells/ normal cell). With use of computer software, it is possible to measure the area under the peaks. Comparing the WT area with the area under the mutant plus the area under one heteroduplex peak gives the mutant fraction. The mutation fraction calculated from the peak areas can be used as a quantitative mearatio between the area [mutant (mut) /WT] is approximately $10^{-3}$. Detection surement of the mutant fraction in a sample. In Figure 1, we found that the

of low-frequency mutations $\left(<10^{-3}\right)$ in this setting is limited by that amount of DNA that is possible to put into a PCR. The normal amount of DNA for a 100$\mu \mathrm{L}$ PCR is $0.1-1.0 \mu \mathrm{g}$ (7). We experienced the upper limit for the amount of DNA possible to have in a $25-\mu \mathrm{L}$ PCR to be approximately $300 \mathrm{ng}$ DNA. This amount of DNA gives an estimate of 1 $\times 10^{5}$ copies of the TP53 gene $(7,20)$. Based on this number of copies, the theoretical detection limit is $10^{-4}$. This is due to the Poisson distribution of the mutants. Given the ratio 10:100000 (mut/WT), the probabilities $(P)$ of getting $>4$ mutants into the PCR is 0.971 . With lower frequencies of mutants, the probabilities of getting the mutant into the PCR will decrease (1 mut/100000 WT, $P[$ mut $\geq 1]=0.632$ ).

The error rate of the enzyme used in the PCR will give a similar limit of detection for low-frequency mutations. $P f u$ DNA polymerase has an error frequency of $1.6 \times 10^{-6}$ errors per base pair doubling $(21,23)$. Because our target sequence is approximately 100-bp long, and we carried out some 35 dou-

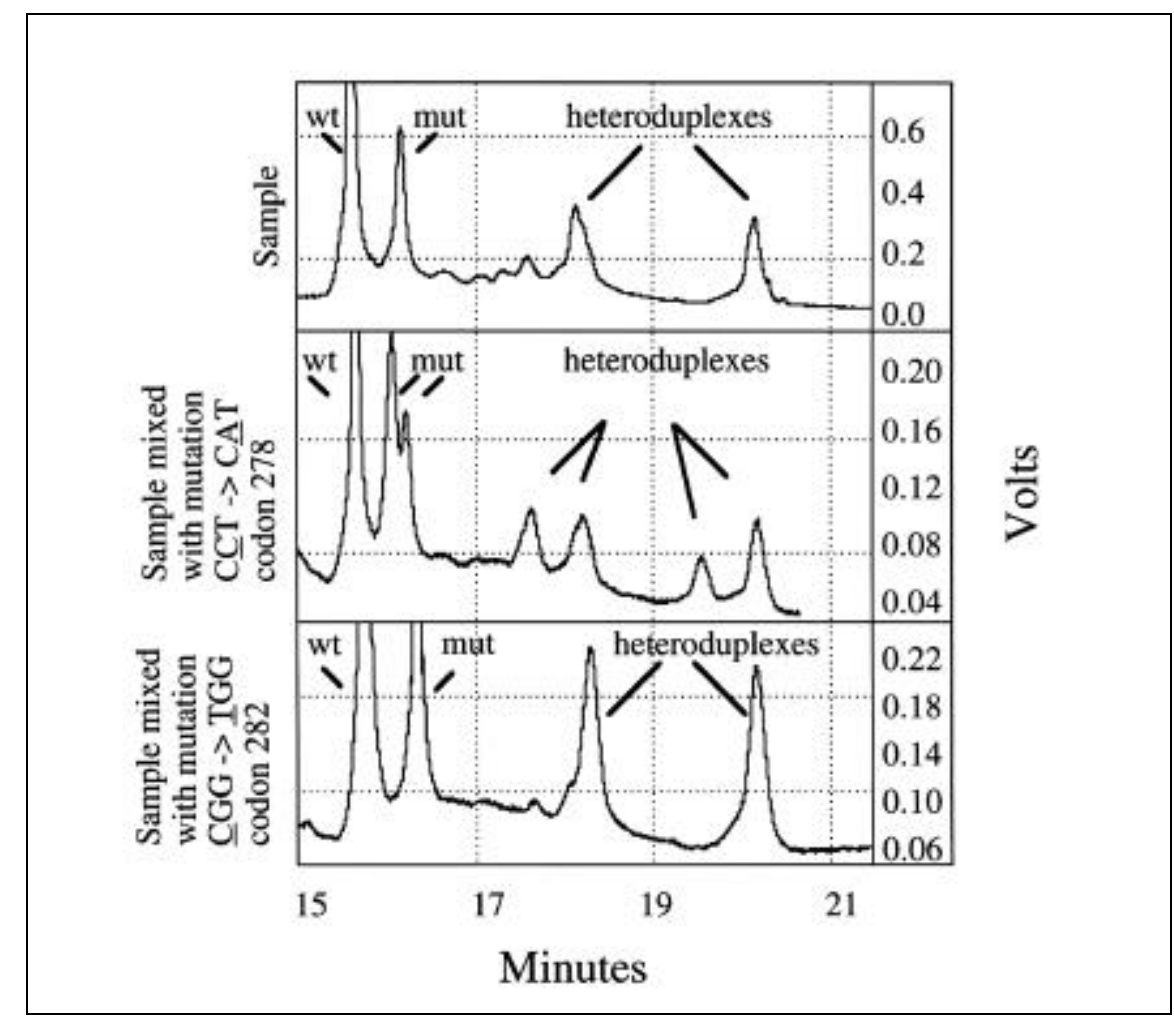

Figure 4. Mutation determination with use of mutation standards. (Upper panel) sample with $\underline{\mathrm{CGG}} \rightarrow$ TGG codon 282 (bp 14 513), (middle panel) C $\underline{\mathrm{CT}} \rightarrow \mathrm{C} \underline{\mathrm{A} T}$ codon 278 (bp 14 502) and (lower panel) $\underline{\mathrm{C} G G} \rightarrow \underline{\mathrm{TGG}}$ codon 282 . blings, we expect a PCR-generated mutant fraction of $1 / 2\left(1.6 \times 10^{-6}\right)(100)(35)$ $=2.8 \times 10^{-3}$. This, divided over several polymerase hot spots, gives a PCR-induced mutation rate of $10^{-4}$.

The linear detection ranges for laser-induced fluorescence is $3 \times 10^{4}$ to $10^{11}$ copies (17). Mixing PCR products from WT and mutants in different ratios, brought detection of heteroduplexes down to $10^{-3}$ (data not shown). This is in accordance with previous findings for human mitochondrial genome and N-ras $(17,18)$ with a similar instrument. The sensitivity can be increased twofold by collecting the heteroduplexes before PCR (16), under the condition of a natural existence of high- and lowmelting domains in the gene fragment of interest. This is done by restriction cutting the genomic DNA, boiling and re-annealing to create heteroduplexes and loading the DNA onto the capillary and running the electrophoresis. Heteroduplexes are separated and collected at the other end of the capillary. Then, the fluorescently labeled PCRs are performed followed by CDCE analysis.

The effect of single base pair substitution on DNA was first described by Fisher and Lerman (9). Base pair substitution will give changes in the DNA stability due to changes in entropy. The changes are due to loss or gain of a hydrogen bond and differences in base pair stacking $(10,24)$. Melting properties of DNA will leave "fingerprints" in the electropherogram that can be used to identify the mutation (12). Figure 2 displays patterns for base pair substitution in the same codon of exon 8 of the TP53 gene. Additionally, we have analyzed ten different mutations from codon 266 to codon 286 (data not shown). All the different mutations we have analyzed so far have displayed a distinct peak pattern with regard to homo- and heteroduplexes. Building up a library of all known mutations in the gene of interest and using software to compare the unknown sample, gives a fast and accurate method of determining the exact sequence alteration in the sample without having to perform laborious sequencing techniques. This can be achieved with a complete database over all mutations and assuming that each mutant has a distinct peak pattern. However, it is possible that two differ- 
ent mutations have a similar peak pattern. This can be circumvented by mixing the two different mutants showing the same peak pattern before analysis to form additional heteroduplexes (12). If the mutants are different, two additional heteroduplexes will appear on the electropherogram (Figure 4).

The determination of the homoduplexes is accomplished by running a sample together with a WT or mutant homoduplex labeled with TMR. The standard will point out which peak of the homoduplexes have the same melting behavior in the capillary. In Figure 3 , the WT standard indicates that the first peak in the upper electropherogram is the WT and, therefore, suggests that the mutations have lower melting temperature and, consequently, increased entropy. The mutation is identified by sequencing to be a $\underline{\mathrm{CGG}} \rightarrow \underline{\mathrm{TGG}}$ in codon 282. As an aide to identification of true peaks in the TMR channel, it is possible to calculate the ratio between the channels. A decrease in the ratio confirms a signal in the TMR channel.

\section{CONCLUSIONS}

This technique can be applied to virtually any known DNA sequence with an iso-melting domain of approximately $100 \mathrm{bp}$ and where a high-temperature melting region can be attached. The size of the PCR product should be approximately $200 \mathrm{bp}$ including a high-temperature melting domain. The sequence used in this study was chosen because of the biological importance in cancer. Under optimal conditions, mutation detection by CDCE can be performed within 20 min after PCR. Combined with a PCR performed in a capillary air themal cycler, it should be possible to have a sample analyzed for mutation in TP53 exon 8 within 60 min. This method has a detection range of $10^{-3}$, ratio mut/WT, and using com- puter software, it is possible to calculate the ratio between the WT and the mutation. Recognition of the sequence alteration of the mutants by use of mutation standards can be applied. This method has an advantage over the radioactive manual sequencing in both time and sensitivity and also the advantage of not using radioactive material. With speed and sensitivity, the CDCE can be adapted to investigations of the molecular status of TP53 in surgical samples surrounding tumors, in premalignant tissue and in tumor cells in the circulation, urine or sputum.

\section{ACKNOWLEDGMENTS}

A sincere thanks to Drs. John Hanekamp and Paulo André of MIT who shared their knowledge of building and running the CDCE/LIF instrument. This work was a collaboration between the Center for Environmental Health 
Sciences, MIT, Cambridge, MA (US National Institute of Environmental Health Sciences (NIEHS) Grants No. P01-ES07168, Mutagenic Effects of Air-borne Toxicants No. P42-ES04675, Superfund Basic Research and No. P01-ES03926, Genetics and Toxicology) and the Department of Genetics, Institute for Cancer Research at The Norwegian Radium Hospital (grants from The Norwegian Cancer Society).

\section{REFERENCES}

1.Andersen, T.I., R. Holm, J.M. Nesland, K.R. Heimdal, L. Ottestad and A.L. Børresen. 1993. Prognostic significance of TP53 alterations in breast carcinoma. Br. J. Cancer 68:540-548.

2.ATCC. 1992. Cell Lines \& Hybridomas. Rockville, MD.

3.Benhattar, J., J.P. Cerottini, E. Saraga, G. Metthez and J.C. Givel. 1996. p53 mutations as a possible predictor of response to chemotherapy in metastatic colorectal carcinomas. Int. J. Cancer 69:190-192.

4.Børresen, A.L., T.I. Andersen, J.E. Eyfjord, R.S. Cornelis, S. Thorlacius, A. Borg, U. Johansson, C. Theillet et al. 1995. TP53 mutations and breast cancer prognosis: particularly poor survival rates for cases with mutations in the zinc-binding domains. Genes Chromosom. Cancer 14:71-75.

5.Børresen, A.L., E. Hovig, S.B. Smith, D. Malkin, S. Lystad, T.I. Andersen, J.M. Nesland, K.J. Isselbacher and S.H. Friend. 1991. Constant denaturant gel electrophoresis as a rapid screening technique for p53 mutations. Proc. Natl. Acad. Sci. USA 88:84058409.

6.Brennan, J.A., L. Mao, R.H. Hruban, J.O. Boyle, Y.J. Eby, W.M. Koch, S.N. Goodman and D. Sidransky. 1995. Molecular assessment of histopathological staging in squamous-cell carcinoma of the head and neck [see comments]. N. Engl. J. Med. 332:429-435.

7.Cha, R.S. and W.G. Thilly. 1993. Specificity, efficiency, and fidelity of PCR. PCR Methods Appl. 3:18-29.

8.Feinmesser, R., I. Miyazaki, R. Cheung, J.L. Freeman, A.M. Noyek and H.M. Dosch. 1992. Diagnosis of nasopharyngeal carcinoma by DNA amplification of tissue obtained by fine-needle aspiration [see comments]. $\mathrm{N}$. Engl. J. Med. 326:17-21.

9.Fischer, S.G. and L.S. Lerman. 1983. DNA fragments differing by single base-pair substitutions are separated in denaturing gradient gels: correspondence with melting theory. Proc. Natl. Acad. Sci. USA 80:1579-1583.

10.Fixman, M. and J.J. Freire. 1977. Theory of DNA melting curves. Biopolymers 16:26932704.

11.Greenblatt, M.S., W.P. Bennett, M. Hollstein and C.C. Harris. 1994. Mutations in the p53 tumor suppressor gene: clues to cancer etiology and molecular pathogenesis. Cancer Res. 54:4855-4878.

12.Guldberg, P. and F. Guttler. 1993. A simple method for identification of point mutations using denaturing gradient gel electrophoresis. Nucleic Acids. Res. 21:2261-2262.

13.Hjertén, S. 1985. High-performance electrophoresis elimination of electroendosmosis and solute adsorption. J. Chromatog. 347:191-198.

14.Hollstein, M., D. Sidransky, B. Vogelstein and C.C. Harris. 1991. p53 mutations in human cancers. Science 253:49-53.

15.Hovig, E., S.B. Smith, A. Brøgger and A.L. Børresen. 1991. Constant denaturant gel electrophoresis, a modification of denaturing gradient gel electrophoresis, in mutation detection [published erratum appears in Mutat. Res. 1991. May 263:61]. Mutat. Res. 262:63-71.

16.Khrapko, K., P. Andre, R. Cha, G. Hu and W.G. Thilly. 1994. Mutational spectrometry: means and ends. Prog. Nucleic. Acid Res. Mol. Biol. 49:285-312.

17.Khrapko, K., J.S. Hanekamp, W.G. Thilly, A. Belenkii, F. Foret and B.L. Karger. 1994. Constant denaturant capillary electrophoresis (CDCE): a high resolution approach to mutational analysis. Nucleic Acids Res. 22:364369.

18.Kumar, R., J.S. Hanekamp, J. Louhelainen, K. Burvall, A. Önfelt, K. Hemminki and W.G. Thilly. 1995. Separation of transforming amino acid-substituting mutations in codons 12,13 and 61 the N-ras gene by constant denaturant capillary electrophoresis (CDCE). Carcinogenesis 16:2667-2673.

19.Levine, A.J., M.E. Perry, A. Chang, A. Silver, D. Dittmer, M. Wu and D. Welsh. 1994. The 1993 Walter Hubert Lecture: the role of the p53 tumour-suppressor gene in tumorigenesis. Br. J. Cancer 69:409-416.

20.Lewin, B. 1994. Genome Size and Genetic Content. Oxford University Press, Oxford.

21.Lundberg, K.S., D.D. Shoemaker, M.W. Adams, J.M. Short, J.A. Sorge and E.J. Mathur. 1991. High-fidelity amplification using a thermostable DNA polymerase isolated from Pyrococcus furiosus. Gene 108:1-6.

22.Morrin, M., M. Kelly, N. Barrett and P. Delaney. 1994. Mutations of $\mathrm{Ki}$-ras and $\mathrm{p} 53$ genes in colorectal cancer and their prognostic significance. Gut 35:1627-1631.

23.Picard, V., B.E. Ersdal, A. Lu and S.C. Bock. 1994. A rapid and efficient one-tube PCR-based mutagenesis technique using Pfu DNA polymerase. Nucleic Acids. Res. 22:2587-2591.

24.Poland, D. 1974. Recursion relation generation of probability profiles for specific-sequence macromolecules with long-range correlations. Biopolymers 13:1859-1871.

25.Pricolo, V.E., S.D. Finkelstein, T.T. Wu, G. Keller, A. Bakker, P.A. Swalsky and K.I. Bland. 1996. Prognostic value of TP53 and Kras-2 mutational analysis in stage III carcinoma of the colon. Am. J. Surg. 171:41-46.

26.Ruiz, M.M., J. Berka, A. Belenkii, F. Foret, A.W. Miller and B.L. Karger. 1993. DNA sequencing by capillary electrophoresis with replaceable linear polyacrylamide and laser-induced fluorescence detection. Anal. Chem. 65:2851-2858.

27.Sidransky, D., T. Tokino, S.R. Hamilton, K.W. Kinzler, B. Levin, P. Frost and B. Vogelstein. 1992. Identification of ras oncogene mutations in the stool of patients with curable colorectal tumors. Science 256:102-105.

28.Thilly, W.G. 1985. Potential use of gradient denaturing gel electrophoresis in obtaining mutational spectra from human cells. Carcinog. Compr. Surv. 10:511-528.

29.Thorstensen, L., H. Quist, J.M. Nesland, K.E. Giercksky and R.A. Lothe. 1996. Allelotype profiles of local recurrences and distant metastases from colorectal cancer patients. Int. J. Cancer 69:452-456.

30.Vogelstein, B. 1990. Cancer. A deadly inheritance [news; comment]. Nature 348:681-682.

31.Wattel, E., C. Preudhomme, B. Hecquet, M. Vanrumbeke, B. Quesnel, I. Dervite, P. Morel and P. Fenaux. 1994. p53 mutations are associated with resistance to chemotherapy and short survival in hematologic malignancies. Blood 84:3148-3157.

Received 17 December 1998; accepted 29 March 1999.

Address correspondence to:

Dr. Per O. Ekstrøm

Center for Environmental Health Sciences

Massachusetts Institute of Technology

Cambridge, MA 02139, USA

Internet: perolaf@mit.edu 